\title{
Growth and molecular interactions of the anti-EGFR antibody Cetuximab and the DNA cross-linking agent cisplatin in gefitinib-resistant MDA-MB-468 cells: New prospects in the treatment of triple-negative/basal-like breast cancer
}

\author{
CRISTINA OLIVERAS-FERRAROS ${ }^{1,2}$, ALEJANDRO VAZQUEZ-MARTIN ${ }^{1,2}$, EUGENI LÓPEZ-BONET ${ }^{3}$, \\ BEGOÑA MARTÍN-CASTILLO ${ }^{1,2}$, SONIA DEL BARCO ${ }^{1}$, JOAN BRUNET ${ }^{1,2}$ and JAVIER A. MENENDEZ ${ }^{1,2}$ \\ ${ }^{1}$ Catalan Institute of Oncology (ICO), ${ }^{2}$ Girona Biomedical Research Institute (IdIBGi), \\ ${ }^{3}$ Department of Pathology, Dr Josep Trueta University Hospital of Girona, Girona, Catalonia, Spain
}

Received June 5, 2008; Accepted September 2, 2008

DOI: 10.3892/ijo_00000106

\begin{abstract}
Three prominent hallmarks of triple-negative/ basal-like breast carcinomas, a subtype of breast cancer gene phenotype associated with poor relapse-free and overall survival, are overexpression of the epidermal growth factor receptor (EGFR), hyperactivation of the MEK/ERK transduction pathway and high sensitivity to DNA-damaging agents. The cytotoxic interaction between EGFR inhibitors (monoclonal antibodies such as Cetuximab and small molecule tyrosine kinase inhibitors such as gefitinib) and DNA cross-linking agents (e.g. platinum derivatives) might represent a promising combination for the treatment of triplenegative/basal-like breast tumors that are dependent upon EGFR/MEK/ERK signaling. We evaluated the growth and molecular interactions of the anti-EGFR antibody Cetuximab $\left(\right.$ Erbitux $^{\circledR}$ ) and the DNA cross-linking agent cisplatin (cisdiammedichloroplatinum; CDDP) in the gefitinib-resistant MDA-MB-468 breast cancer cell line, an in vitro model system that shows many of the recurrent basal-like molecular abnormalities including ER-PR-HER2-negative status, TP53 deficiency, EGFR overexpression, PTEN loss and constitutive activation of the MEK/ERK pathway. Unlike other basal-like breast cancer models, MDA-MB-468 cells do not carry mutations of the key DNA repair gene BRCA1. Concurrent treatment with sub-optimal doses of Cetuximab significantly enhanced CDDP-induced apoptotic cell death. However, an isobologram-based mathematical assessment of the nature of the interaction revealed a loss of synergism when employing a high-dose of Cetuximab. Since BRCA1 depletion has been
\end{abstract}

Correspondence to: Dr Javier A. Menendez, Catalan Institute of Oncology-Girona (ICO Girona), Dr Josep Trueta University Hospital of Girona, Avenida de Francia s/n, E-17007 Girona, Catalonia, Spain E-mail: jmenendez@ico.scs.es or jmenendez@iconcologia.net

Key words: Cetuximab, cisplatin, basal-like, epidermal growth factor receptor, mitogen-activated protein kinases, BRCA1 found to decrease DNA damage repair and cell survival in MDA-MB-468 cells when treated with DNA-damaging drugs, we employed ELISA-based quantitative analyses to measure BRCA1 protein levels in $\mathrm{CDDP}^{+/-}$Cetuximabtreated cells. Cetuximab as single agent was as efficient as CDDP at increasing BRCA1 protein expression. Interestingly, Cetuximab co-exposure significantly antagonized the ability of CDDP to up-regulate BRCA1 expression. Low-scale phosphor-proteomic approaches [i.e. phospho-receptor tyrosine kinase (RTK) and phosphomitogen-activated protein kinases (MAPKs) Array Proteome Profiler $^{\mathrm{TM}}$ capable of simultaneously identifying the relative levels of phosphorylation of 42 different RTKs and 23 different MAPKs and other serine/threonine kinases, respectively] revealed the ability of Cetuximab, as single agent, to paradoxically induce hyper-phosphorylation of EGFR while concomitantly deactivating p42/44 (ERK1/ ERK2) MAPK. Unexpectedly, ELISA-based quantitative analyses of EGFR protein content demonstrated that simultaneous exposure to Cetuximab and optimal doses of CDDP completely depleted EGFR protein in MDA-MB-468 cells. Although these findings preclinically support, at least in part, ongoing clinical trials for 'triple-negative/basal-like' metastatic breast cancer patients who are receiving either Cetuximab alone versus Cetuximab plus carboplatin (http://www.clinicaltrials.gov/ct/show/NCT00232505), the unexpected ability of CDDP to promote a complete depletion of the Cetuximab target EGFR further suggests that treatment schedules, Cetuximab/CDDP doses and BRCA1 status should be carefully considered when combining anti-EGFR antibodies and platinum derivatives in triple-negative/basal-like breast carcinomas.

\section{Introduction}

Gene expression profiling has revealed that, despite the enormous genetic diversity of breast cancer disease, each breast tumor can be classified into one of four major breast cancer subtypes: luminal [estrogen receptor-positive tumors that express ER-responsive genes and other genes that encode 
characteristic proteins of luminal epithelial cells including the progesterone receptor (PR)], human epidermal growth factor receptor 2 [(HER2/ErbB2), which express high levels of genes located in the HER2 amplicon on 17q21, including HER2 and growth factor receptor-bound protein 7 (GRB7)], basal-like [ER-, PR- and HER2-negative (triple-negative) breast tumors expressing genes characteristics of basal epithelial cells and normal breast myoepithelial cells], and normal-breast like (breast tumors that express non-epithelial genes and genes in the basal cluster) (1-5). Basal-like breast carcinomas account for $15-25 \%$ of all breast cancer cases and, together with HER2 tumors, they associate with the shortest survival of all four breast cancer subtypes with early relapses within the first five years (6-10). Unfortunately, basal-like do not express ER or HER2 and are typically refractory to endocrine therapy and to trastuzumab (Herceptin ${ }^{\mathrm{TM}}$ ), a humanized monoclonal antibody targeting the extracellular domain of HER2 (11).

New molecular prospects for targeted treatment of basallike breast cancer tumors have emerged recently. First, high expression of the epidermal growth factor receptor 1 (EGFR/ HER1) has been reported in an important sub-set of basallike breast tumors and, therefore, drugs directed against this receptor (e.g., monoclonal antibodies binding the extracellular ligand-binding domain of EGFR and small molecule inhibiting the intracellular tyrosine kinase domain of EGFR) may represent a promising approach for the treatment of basal-like breast tumors that are dependent upon exacerbated EGFRsignaling (6). Second, the observation that many of the gene products in the basal-like cluster have been linked to MEK/ ERK activation suggests that this signaling pathway might have a central role in the pathogenesis of basal-like breast carcinomas (11-13). Moreover, the MEK/ERK pathway may play a more important role in resistance of basal-like breast cancer cells to EGFR inhibitors such as the tyrosine kinase inhibitor (TKI) gefitinib (Iressa $\left.{ }^{\circledR}\right)(14,15)$. Third, the striking similarities between sporadic basal-like and hereditary BRCA1-related breast carcinomas suggest that a fundamental defect in the BRCA1-regulated DNA repair pathway also occurs in basal-like tumors (16-18). Therefore, new therapeutic strategies combining potential DNA-damaging agents (e.g., DNA cross-linking agents such as platinum derivatives and agents inducing DNA double-strand breaks such as etoposide) and inhibitors of the EGFR/MEK/ERK pathway might be efficacious in the molecular management of basal-like breast carcinomas that are dependent upon EGFR overactivation and/or BRCA1 dysfunction.

We examined the growth and molecular interactions that occur upon concurrent treatment with the anti-EGFR antibody Cetuximab (ICM-C225, Erbitux ${ }^{\mathrm{TM}}$ ) and the alkylating agent cisplatin (CDDP) when employing the MDA-MB-468 breast cancer cell line, an in vitro paradigm of intrinsic resistance to EGFR TKIs that shows many of the recurrent basal-like molecular abnormalities including ER-PR-HER2negative status, TP53 deficiency, EGFR overexpression, PTEN loss and constitutive activation of the MEK/ERK pathway.

\section{Materials and methods}

Reagents. Cetuximab (Erbitux ${ }^{\circledR}$ ) and Cisplatin (cisdiammedichloroplatinum; CDDP) were kindly provided by
Hospital Universitari de Girona Dr Josep Trueta Pharmacy (Girona, Spain). Cetuximab was solubilized with $10 \mathrm{mM} \mathrm{NaCl}$ of potassium phosphate buffer $\mathrm{pH} 7.2$ in bacteriostatic water for injection purposes (stock solution at $2 \mathrm{mg} / \mathrm{ml}$ ), stored at $4^{\circ} \mathrm{C}$ and used within one month. Each $\mathrm{ml}$ of sterile, unpreserved solution of 'Cisplatin Injection' (stock solution at $1 \mathrm{mg} / \mathrm{ml}$ ) contained $1.0 \mathrm{mg} \mathrm{CDDP}$ with $9 \mathrm{mg} \mathrm{NaCl}$ and $1 \mathrm{mg}$ mannitol in water for injection purposes. Hydrochloric acid was added to adjust the $\mathrm{pH}$. For experimental use, Cetuximab and CDDP were prepared freshly from stock solutions and diluted with growth medium. Control cells were cultured in medium containing the same concentration $(\mathrm{v} / \mathrm{v})$ as the experimental cultures with treatments. The vehicle solutions had no noticeable influence on the proliferation of experimental cells.

Cell lines and culture conditions. MCF-7, SKBR3 and MDA-MB-468 breast cancer cell lines were obtained from the American Type Culture Collection (ATCC) and they were routinely grown in Dulbecco's modified Eagle's medium (DMEM, Gibco) containing 10\% heat-inactivated foetal bovine serum (FBS, Bio-Whittaker), 1\% L-glutamine, 1\% sodium pyruvate, $50 \mathrm{U} / \mathrm{ml}$ penicillin and $50 \mu \mathrm{g} / \mathrm{ml}$ streptomycin. Cells were maintained at $37^{\circ} \mathrm{C}$ in a humidified atmosphere of $95 \%$ air/5\% $\mathrm{CO}_{2}$. MCF10A normal breast epithelial cells (ATCC) were cultured in Dulbecco's modified Eagle's medium (DMEM):Ham's F-12 supplemented with $10 \%$ horse serum, $10 \mathrm{mM}$ HEPES buffer, $10 \mathrm{ng} / \mathrm{ml}$ insulin, $20 \mathrm{ng} / \mathrm{ml} \mathrm{EGF}, 100 \mathrm{ng} / \mathrm{ml}$ cholera toxin and $0.5 \mathrm{mg} / \mathrm{ml}$ hydrocortisone. Cells were fed twice a week and passaged on a weekly basis. Cells were maintained at $37^{\circ} \mathrm{C}$ in a humidified atmosphere of $95 \%$ air and $5 \% \mathrm{CO}_{2}$. Cells were screened periodically for Mycoplasma contamination.

Metabolic status assessment (MTT-based cell viability assays). The ability of Cetuximab, CDDP and Cetuximab + CDDP to affect breast cancer cell viability was determined using a standard colorimetric MTT (3-4, 5-dimethylthiazol-2-yl-2, 5diphenyl-tetrazolium bromide) reduction assay. Cells in exponential growth were harvested by trypsinization and seeded at a concentration of $\sim 2.5 \times 10^{3}$ cells $/ 200 \mu 1 /$ well into 96-well plates and allowed an overnight period for attachment. Then the medium was removed and fresh medium along with various concentrations of Cetuximab, CDDP or combinations of compounds as specified, were added to cultures in parallel. Agents were studied in combination concurrently. Control cells without agents were cultured using the same conditions with comparable media changes. Compounds were not renewed during the entire period of cell exposure. Following treatment ( 5 days), the medium was removed and replaced by fresh drug-free medium (100 $\mu \mathrm{l} / \mathrm{well})$ and MTT $(5 \mathrm{mg} / \mathrm{ml}$ in PBS) was added to each well at a 1/10 volume. After incubation for $2-3 \mathrm{~h}$ at $37^{\circ} \mathrm{C}$, the supernatants were carefully aspirated, $100 \mu 1$ of DMSO were added to each well and the plates agitated to dissolve the crystal product. Absorbances were measured at $570 \mathrm{~nm}$ using a multi-well plate reader (Model Anthos Labtec 20101.7 reader). The cell viability effects from exposure of cells to each agent alone and their combination were analyzed as percentages of the control cell absorbances, which were obtained from control wells treated 
with appropriate concentrations of the compound vehicles that were processed simultaneously. For each treatment, cell viability was evaluated as a percentage using the following equation: $\left(\mathrm{A}_{570}\right.$ of treated sample/ $\mathrm{A}_{570}$ of untreated sample) $\mathrm{x} 100$.

Breast cancer cell sensitivity to Cetuximab and/or CDDP was expressed in terms of the concentration of drug required to decrease by $50 \%$ cell viability $\left(\mathrm{IC}_{50}\right.$ value). Since the percentage of control absorbance was considered to be the surviving fraction of cells, the $\mathrm{IC}_{50}$ value was defined as the concentration of Cetuximab and/or CDDP that produced 50\% reduction in control absorbance (by interpolation), respectively. The degree of sensitization to CDDP by Cetuximab was evaluated by dividing $\mathrm{IC}_{50}$ values of control cells (CDDP alone) by those obtained when cells were simultaneously exposed to Cetuximab.

Determination of synergism and antagonism: Isobologram analysis. The nature of the interaction between Cetuximab and CDDP was evaluated by the isobologram technique, a dose-oriented geometric method of assessing drug interactions (19). In the isobologram method the concentration of one agent producing a desired (e.g., 50\% inhibitory) effect is plotted on the horizontal axis and the concentration of another agent producing the same degree of effect is plotted on the vertical axis; a straight line joining these 2 points represents zero interaction (addition) between two agents. The experimental isoeffect points are the concentrations (expressed relative to the $\mathrm{IC}_{50}$ value) of the two agents which when combined decreased cell viability by $50 \%$. When the experimental isoeffect points fall below that line, the combination effect of the two drugs is considered to be supraadditive or synergistic, whereas antagonism occurs if the point lies above it. A quantitative index of these interactions was provided by the isobologram equation $\mathrm{CI}_{50}=(\mathrm{a} / \mathrm{A})+(\mathrm{b} / \mathrm{B})$, where, for this study, $\mathrm{A}$ and $\mathrm{B}$ represent the respective concentrations of Cetuximab and CDDP required to produce a fixed level of inhibition $\left(\mathrm{IC}_{50}\right)$ when administered alone, $\mathrm{a}$ and $\mathrm{b}$ represent the concentrations required for the same effect when Cetuximab and CDDP were administered in simultaneous combination and $\mathrm{CI}_{50}$ represents an index of drug interaction (Combination Index). CI values of $<1$ indicate synergy, a value of 1 represents addition and values of $>1$ indicate antagonism. For all estimations of $\mathrm{CI}_{50}$, we used only isoboles where intercept data for both axes were available.

Apoptosis assays. Quantification of apoptosis-related cell death was assessed using the Cell Death Detection ELISA ${ }^{\text {PLuS }}$ kit obtained from Roche Diagnostics (Barcelona, Spain). Briefly, cells ( 5 to $10 \times 10^{3} /$ well) were grown in 96-well plates and treated, in duplicates, for $72 \mathrm{~h}$ with the indicated doses of Cetuximab, CDDP, or Cetuximab plus CDDP as specified. After treatment, the 96-well plates were centrifuged (200 x g) for $10 \mathrm{~min}$. The supernatant was discharged, lysis buffer was added and samples were incubated at room temperature (RT) for $30 \mathrm{~min}$. Anti-histone biotin and anti-DNA peroxidase antibodies were added to each well and incubated at RT for $2 \mathrm{~h}$. After three washes, the peroxidase substrate was added to each well and the plates were read at $405 \mathrm{~nm}$ at multiple time intervals with using a reference filter at $490 \mathrm{~nm}$. The enrichment of histone-DNA fragments in treated cells was expressed as fold increase in absorbance by comparing with control (vehicle-treated) cells using the following formula: $\left[\mathrm{A}_{405}-\mathrm{A}_{490}\right]_{\text {TREated }} /\left[\mathrm{A}_{405}-\mathrm{A}_{490}\right]_{\text {UnTREated }}$.

EGFR- and BRCAl-specific enzyme-linked immunosorbent assays. Determination of EGFR and BRCA1 protein content was performed with commercially available quantitative ELISAs (Oncogene Science, Bayer Diagnostics for EGFR and Assay Designs for BRCA1, respectively) according to the manufacturer's protocol. To assess the effects of Cetuximab and/or CDDP on EGFR and BRCA1 protein concentrations, breast cancer cells, after a $24 \mathrm{~h}$ starvation period in media without serum, were incubated with Cetuximab, CDDP or combinations of these compounds as specified. After treatment, cells were washed twice with cold-PBS and then lysed in buffer $(20 \mathrm{mM}$ Tris $\mathrm{pH} 7.5,150 \mathrm{mM} \mathrm{NaCl}, 1 \mathrm{mM}$ EDTA, $1 \mathrm{mM}$ EGTA, 1\% Triton X-100, $2.5 \mathrm{mM}$ sodium pyrophosphate, $1 \mathrm{mM} ß$-glycerolphosphate, $1 \mathrm{mM} \mathrm{Na}_{3} \mathrm{VO}_{4}$, $1 \mu \mathrm{g} / \mathrm{ml}$ leupeptin, $1 \mathrm{mM}$ phenylmethylsulfonylfluoride) for $30 \mathrm{~min}$ on ice. The lysates were cleared by centrifugation in an Eppendorff tube $\left(15 \mathrm{~min}\right.$ at $\left.14,000 \mathrm{x} \mathrm{g}, 4^{\circ} \mathrm{C}\right)$. Protein content was determined against a standardized control using the Pierce Protein Assay kit.

Serial dilutions (i.e., 1:50 and 1:500 for EGFR and 1:10 and 1:100 for BRCA1) of total cell lysates from Cetuximab-, CDDP- and Cetuximab + CDDP-treated and control untreated MDA-MB-468 breast cancer cells were used to quantitate EGFR and BRCA1 protein expression in cell cultures. A standard curve was generated by using standard solutions as per the manufacturer's instructions. The concentrations of EGFR and BRCA1 in test samples (in nanograms of EGFR per milligram of total protein and pg of BRCA1 per milligram of total protein, respectively) were determined by interpolation of the sample absorbances from the standard curve. Each experiment was performed in duplicate wells.

Phosphor-proteome profiling. Cells were rinsed with cold-PBS and immediately solubilized in NP-40 lysis buffer [1\% NP-40, $20 \mathrm{mM}$ Tris- $\mathrm{HCl}$ (pH 8.0), $137 \mathrm{mM} \mathrm{NaCl}, 10 \%$ glycerol, $2 \mathrm{mM}$ EDTA, $1 \mathrm{mM}$ sodium orthovanadate, $10 \mu \mathrm{g} / \mathrm{ml}$ aprotinin, $10 \mu \mathrm{g} / \mathrm{ml}$ leupeptin] by rocking the lysates gently at $4^{\circ} \mathrm{C}$ for $30 \mathrm{~min}$. Following microcentrifugation at $14,000 \mathrm{x} \mathrm{g}$ for $5 \mathrm{~min}$, supernatants were transferred into a clean test tube and sample protein concentrations were determined using the Pierce Protein assay kit (Rockford, IL). Lysates $(500 \mu \mathrm{g})$ were diluted and incubated with Human Phospho-RTK and Human Phospho-MAPK Arrays (Proteome Profiler; R\&D Systems; Minneapolis, MN, USA) as per the manufacturer's instructions. Array data were developed on X-ray film following exposure to chemiluminescent reagents.

Statistics. Two-group comparisons were performed by the Student's t-test for paired and unpaired values. Comparisons of means of $\geq 3$ groups were performed by ANOVA and the existence of individual differences, in case of significant $\mathrm{F}$ values at ANOVA, tested by Scheffé's multiple contrasts. 

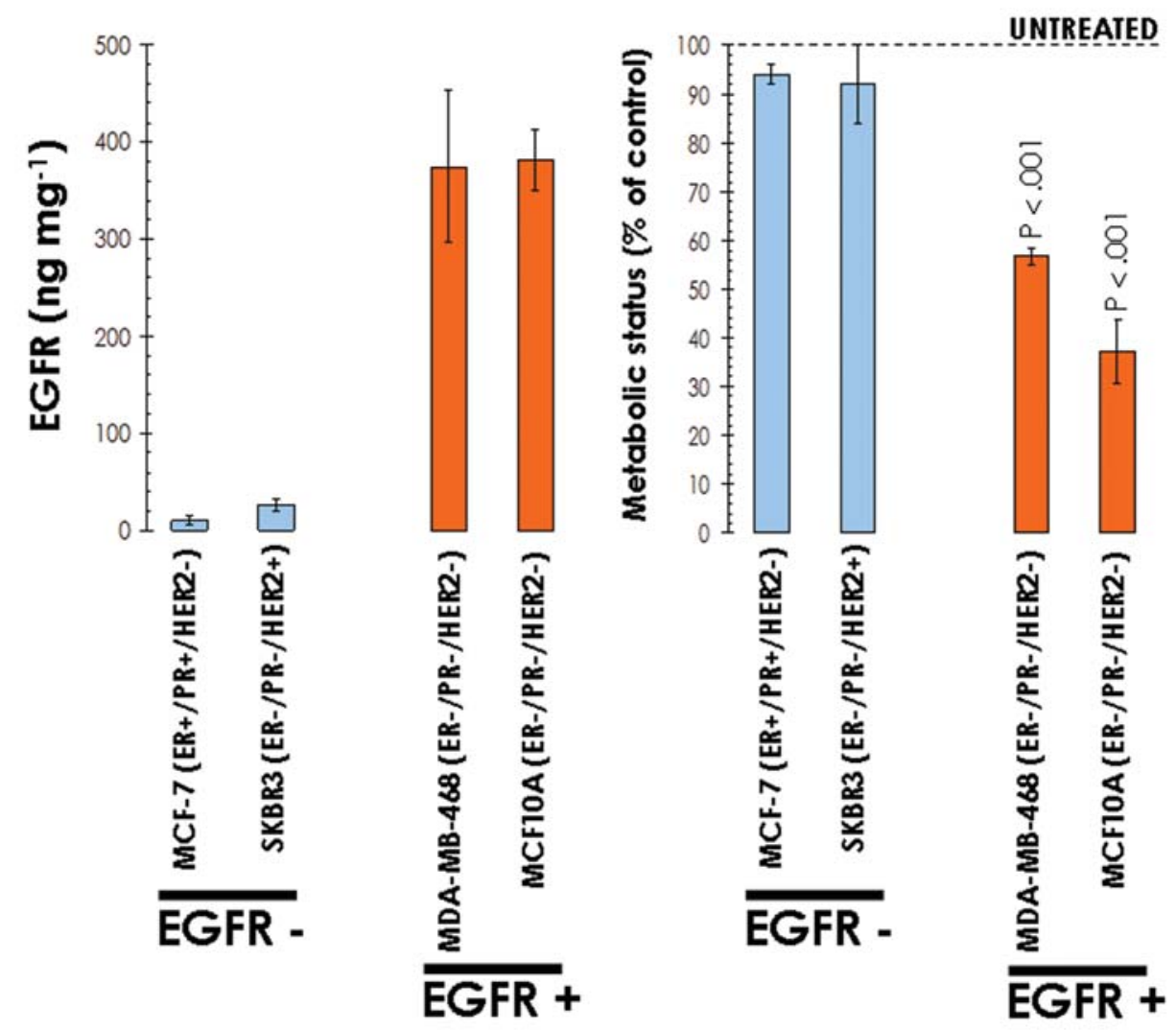

Figure 1. Correlation between EGFR protein expression and Cetuximab responsiveness in human breast epithelial cells. (Left) Overnight serum-starved MCF-7, SKBR3, MDA-MB-468 and MCF10A cells were cultured in standard culture conditions for 48 h. The Oncogene Science HER1 (EGFR) microtiter ELISA was used according to the manufacturer's instructions to quantitatively evaluate HER1 concentrations (ng of EGFR per mg of protein) in whole cell lysates. Results are means (columns) and 95\% confidence intervals (bars) of three independent experiments made in triplicate. (Right) MCF-7, SKBR3, MDA-MB468 and MCF10A cells were incubated with $200 \mu \mathrm{g} / \mathrm{ml}$ Cetuximab for $\sim 5$ days. Cell growth, measured using MTT assays, was expressed as $\%$ of untreated cells (dashed line, $100 \%$ cell viability). Results are means (columns) and 95\% confidence intervals (bars) of three independent experiments made in triplicate. Statistically significant differences (one-factor ANOVA analysis) between experimental conditions and unsupplemented control cells are shown. All statistical tests were two-sided.

\section{Results}

Cetuximab induces anti-proliferative effects in basal-like, but not in luminal and HER2+/ER- breast cancer cells. To primarily assess a relationship between breast cancer heterogenicity and breast cancer sensitivity to the EGFR inhibitor Cetuximab, we selected in vitro models of $\mathrm{ER}^{+}$, EGFR-, HER2- breast cancer (i.e. MCF-7 cells), ER-, EGFR', HER2+ breast cancer (SKBR3 cells) and ER-, EGFR ${ }^{+}, \mathrm{HER}^{-}$ basal-like breast cancer (MDA-MB-468) breast cancer phenotypes (Fig. 1). The immortal, non-transformed and EGFR-dependent MCF10A breast epithelial cells, which themselves already appear to display a basal-like gene expression profile (20), was employed as positive control in our experiments. These four cell lines were treated with a range of doses of Cetuximab $(0-200 \mu \mathrm{g} / \mathrm{ml})$ and cell numbers were measured using a tetrazolium salt-based (MTT) cell viability assay (Fig. 1). Cetuximab, as single agent, significantly decreased cell proliferation solely in EGFRoverexpressing MCF10A and MDA-MB-468 basal-like breast cancer cells with no significant effects occurring in EGFRnegative MCF-7 and SKBR3 breast cancer models.

Cetuximab synergistically enhances the pro-apoptotic effects of CDDP in MDA-MB-468 basal-like breast cancer cells. To evaluate how Cetuximab altered the efficacy of DNA crosslinking agents in triple-negative/basal-like breast cancer cells, MDA-MB-468 cells were exposed to increasing concentrations of CDDP $(125,250$ and $500 \mathrm{nM})$ in the absence or presence of low (sub-optimal) and high (optimal) doses of Cetuximab (50 and $200 \mu \mathrm{g} / \mathrm{ml}$, respectively). Apoptotic cell death was measured by a Cell Death ELISA kit that detects apoptosis-induced DNA-histone fragmentation, and the $\mathrm{x}$-fold increase in apoptosis was calculated by comparing the ELISA optical density readings of treated samples, with the values of untreated controls cells as 1.0 -fold (Fig. 2). MDA-MB-468 cells were likewise exquisitely sensitive to the pro-apoptotic effects of CDDP (up to 5-5-fold increase in the presence of $500 \mathrm{nM}$ cisplatin versus 1.0 -fold in untreated control cells). Cetuximab, as single agent, failed to significantly induce apoptotic cell death. MDAMB-468 cells exhibited the highest extent of apoptotic cell death following concurrent exposure to Cetuximab and CDDP (up to 11.6-fold increase when concurrently combining $50 \mu \mathrm{g} / \mathrm{ml}$ Cetuximab and $500 \mathrm{nM}$ CDDP). Interestingly, no-dose dependency of Cetuximab was observed within this synergism. Indeed, $200 \mu \mathrm{g} / \mathrm{ml}$ Cetuximab (a 4-fold higher concentration of the anti-EGFR antibody) failed to further increase CDDP-induced apoptosis in MDA-MB-468 cells. 


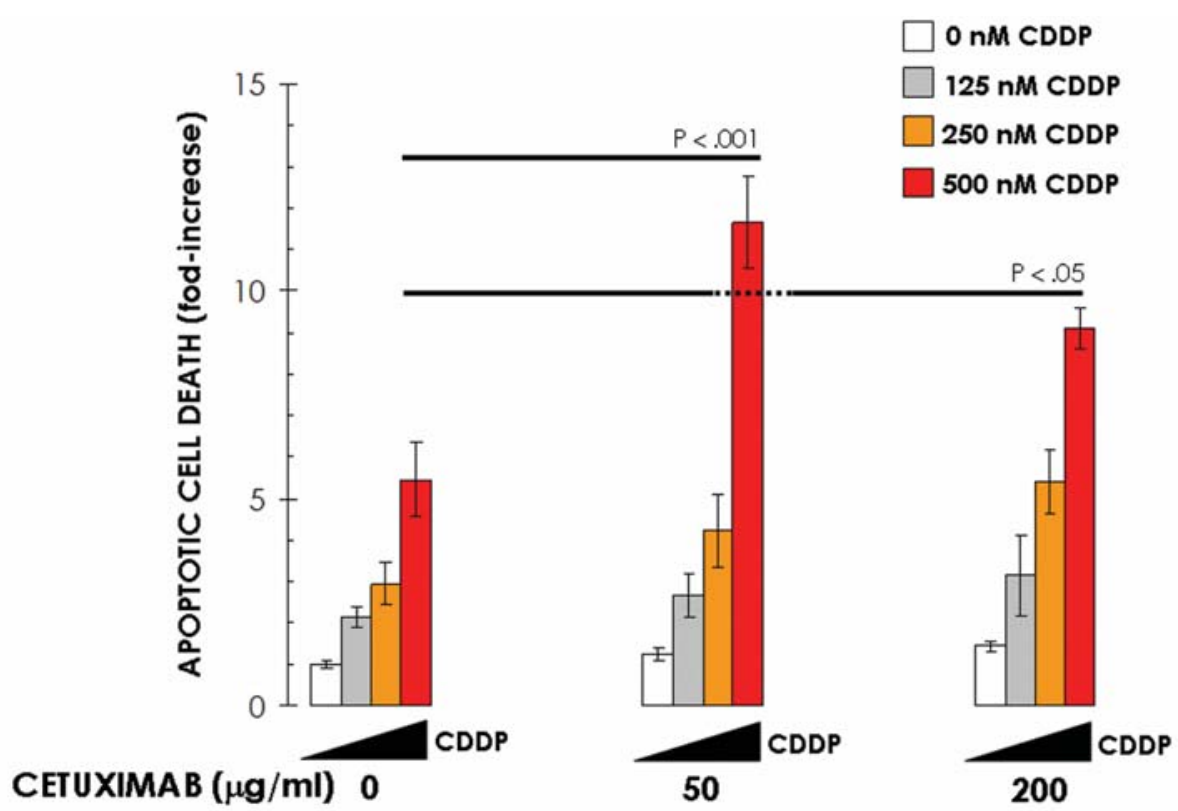

Figure 2. Effects of Cetuximab co-treatment in CDDP-induced apoptosis. Quantification of apoptosis-related cell death in MDA-MB-468 cells treated with increasing concentrations of CDDP in the absence or presence of Cetuximab was determined by Cell Death ELISA as described in 'Materials and methods'. The enrichment of histone-DNA fragments in CDDP and/or Cetuximab-treated cells was expressed as fold-increase in absorbance by comparing with control (vehicle-treated) cells using the following formula: $\left[\mathrm{A}_{405}-\mathrm{A}_{490}\right]_{\text {TREATED }} /\left[\mathrm{A}_{405}-\mathrm{A}_{490}\right]_{\text {UNTREATED}}$. Data are the mean (columns) and $95 \%$ confidence intervals (bars) of three independent experiments performed in duplicate. One-factor ANOVA was used to analyze differences in the percentage of apoptosis between the various treatment groups.

Cetuximab synergistically enhances the anti-proliferative effects of CDDP in MDA-MB-468 basal-like breast cancer cells. The above findings strongly suggested that Cetuximabinduced EGFR blockade can synergistically enhance CDDP efficacy against MDA-MB-468 basal-like breast cancer cells. To further elucidate this question, we monitored Cetuximabinduced changes in the degree of MDA-MB-468 cells sensitivity to CDPP by dividing the $\mathrm{IC}_{50}$ values for CDDP in the absence of Cetuximab by those obtained in cells concurrently exposed to increasing concentrations of Cetuximab. The sensitizing effects of Cetuximab on the antiproliferative effects of CDDP are shown in Fig. 3a. Although the $\mathrm{IC}_{50}$ value of CDDP drastically dropped (up to 135-times) from $270 \mathrm{nM}$ CDDP (95\% CI 260-280 nM) in the absence of Cetuximab to $2 \mathrm{nM}$ CDDP (95\% CI 1-3 nM) in the presence of $200 \mu \mathrm{g} / \mathrm{ml}$ Cetuximab ( $<<0.001$; two-sided ANOVA analysis), it should be noted that there was no dose-dependency in the decrease of CDDP $\mathrm{IC}_{50}$ values after co-exposure to graded amounts of Cetuximab (Fig. 3b).

To accurately delineate the nature of the cytotoxic interaction (i.e., antagonism, addition, synergism or protection) that occurred when simultaneously combining Cetuximab and CDDP, we performed isobologram transformations of the Cetuximab/CDDP cytotoxic effects. A representative transformation is presented graphically (isobologram) in Fig. 3c. The straight line drawn between the $\mathrm{IC}_{50}$ value for CDDP alone and the $\mathrm{IC}_{50}$ value for Cetuximab alone indicates the alignment of theoretical isoeffect data points for additive interactions. The true $\mathrm{IC}_{50}$ values (i.e., the experimental concentrations of Cetuximab and CDDP which combined produced $50 \%$ reduction in cell proliferation) were plotted and compared with the additive line. The experimental isoeffects mostly fell in the left side of the additive line, thus suggesting that a supra-additive (synergistic) effect appears to emerge when combining Cetuximab and CDDO in MDA-MB-468 cells. However, there was not statistically significant difference between the mean Combination Index ${ }_{50}$ value (mean $\mathrm{CI}_{50}=0.701 \pm 0.251$ ) and the null hypothesis for additivity $\left(\mathrm{CI}_{50}=1.0\right)$. Indeed, the degree of synergism between Cetuximab and CDDP related to Cetuximab concentration (Fig. 3c). At low-dose Cetuximab (50 $\mu \mathrm{g} / \mathrm{ml})$, the amount of the two agents necessary to reduce cell proliferation by $50 \%$ was only 0.503 times (i.e., approximately half the dose of each agent) as much as it would be required if they demonstrated purely additive actions in MDA-MB-468 cells. This synergistic behavior disappeared when employing high-dose Cetuximab $(200 \mu \mathrm{g} / \mathrm{ml})$. In this scenario, the amount of the two agents necessary to reduce cell viability by $50 \%$ increased up to 0.983 times, thus denoting a loss of synergism and the appearance of only additive actions. Additive and antagonistic interactions occurred when MDAMB-468 basal-like breast cancer cells were sequentially exposed to Cetuximab prior to CDDP (data not shown).

Cetuximab regulates BRCA1 protein expression in MDA-MB468 basal-like breast cancer cells. Although MDA-MB-468 cells were exquisitely sensitive to CDDP and Cetuximab when applied individually, the above MTT-based cell viability findings strongly suggested that the combination of Cetuximab-induced EGFR blockade and CDDP-induced DNA damage was highly synergistic at low doses of each agent. Interestingly, Cetuximab treatment failed to induce any extent of apoptosis in MDA-MB-468 cell cultures whereas the combination of Cetuximab with high doses of CDDP was also found to be strongly synergistic when analyzing the extent of apoptotic cell death using ELISA-based detection of 
a

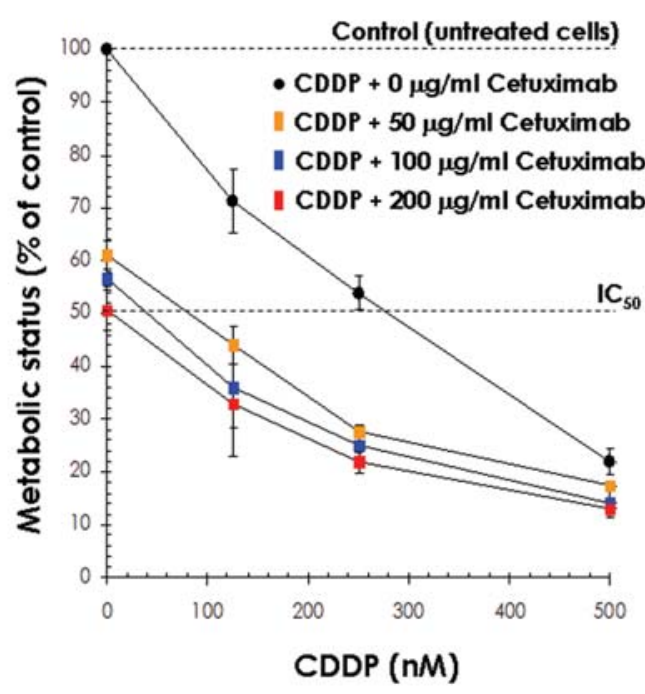

b

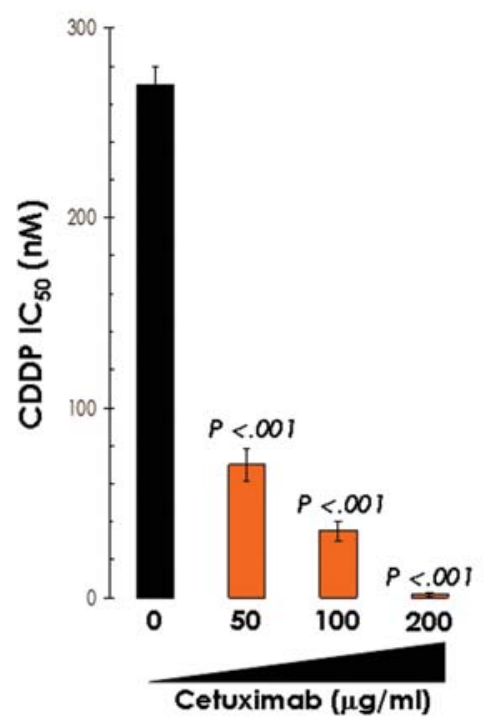

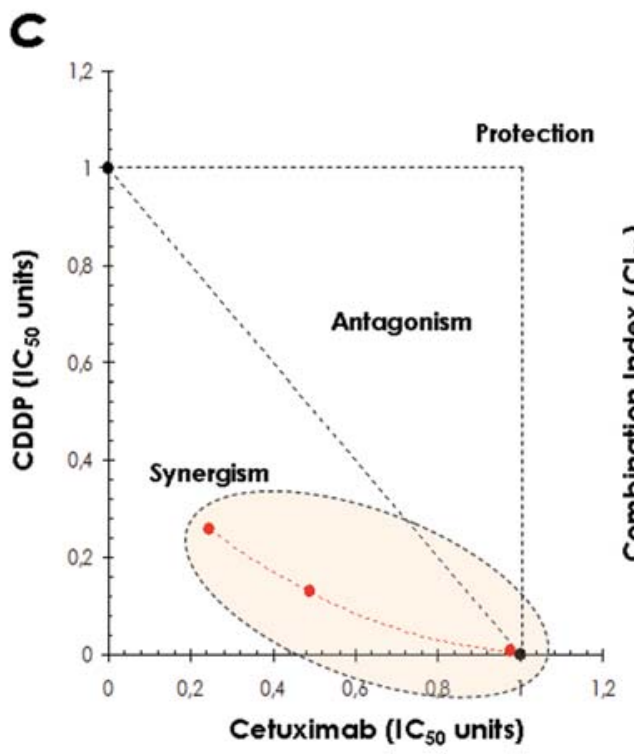

Mean $\mathrm{Cl}_{50}=0.701 \pm 0.251$

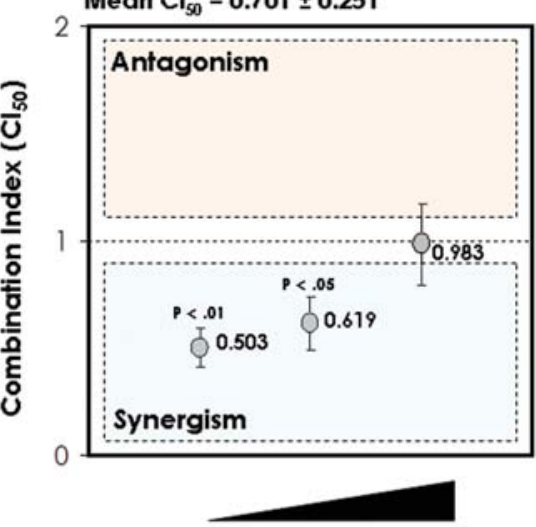

[Cetuximab] $(\mu \mathrm{g} / \mathrm{ml})$

Figure 3. Synergy analyses of the interaction between Cetuximab and CDDP in MDA-MB-468 basal-like breast cancer cells. (a) MDA-MB-468 cells were incubated with or without graded concentrations of CDDP in the absence or presence of increasing concentrations of Cetuximab. Cell growth, measured using MTT assays, was expressed as \% of untreated cells (dashed line, 100\% cell viability). Results are means and $95 \%$ confidence intervals (bars) of five independent experiments made in triplicate. (b) MDA-MB-468 cell line sensitivity to CDDP was expressed in terms of the concentration of drug required to decrease by $50 \%\left(\mathrm{IC}_{50}\right)$ cell viability. Since the percentage of control absorbance in MTT-based cell viability assays (a) was considered to be the surviving fraction of cells, the CDDP IC $_{50}$ values in the absence or presence of grades concentrations of Cetuximab were defined as the concentration of CDDP that produced $50 \%$ reduction in control absorbance (by interpolation). The degree of sensitization to CDDP by Cetuximab was evaluated by dividing $\mathrm{IC}_{50} \mathrm{values}$ of control cells (i.e. $\mathrm{CDDP}_{\mathrm{B}}$ single agent) by those obtained when cells were simultaneously exposed to Cetuximab. (c and d) The nature of the interaction between Cetuximab and CDDP was evaluated by the isobologram technique, a dose-oriented geometric method of assessing drug interactions. Upon this approach, the concentration of Cetuximab producing a desired (e.g. 50\% inhibitory) effect was plotted on the horizontal axis and the concentration of CDDP producing the same growth inhibitory effect was plotted on the vertical axis; a straight line joining these two points represents zero interaction between the two agents $\left(\mathrm{CI}_{50}\right.$, 1.0 , additivity). An experimental isoeffect point is the concentration (expressed relative to Cetuximab and CDDP $\mathrm{IC}_{50}$ concentrations) of the two agents which when combined reduced cell viability by $50 \%$. Within the designed assay range, a set of isoeffect points was generated because there were multiple Cetuximab and CDDP concentrations that achieved the same isoeffect. In our present study, the mean values of the survival fractions were used to generate the set of experimental isoeffect points and construct the isobole for the Cetuximab-CDDP combination. Data points above the diagonal line of the additive effects in the isobole suggest antagonism and those below the diagonal suggest synergism. The values of the mean $\mathrm{CI}_{50}$ values are also represented as a function of Cetuximab concentration. Student t-tests were applied to formally evaluate whether synergism was evident as compared to a null-hypothesized $\mathrm{CI}_{50}$ of 1.0 .

histone-associate DNA fragments. We hypothesized that Cetuximab-induced blockade of EGFR should result in the alteration of the DNA repair machinery in triple-negative/ basal-like breast carcinoma cells.
A major contributing factor to the exquisite sensitivity of triple-negative/basal-like breast cancer agents to DNAdamaging agents including CDDP is decreased functional expression of breast cancer susceptibility gene 1 (BRCA1) 
a

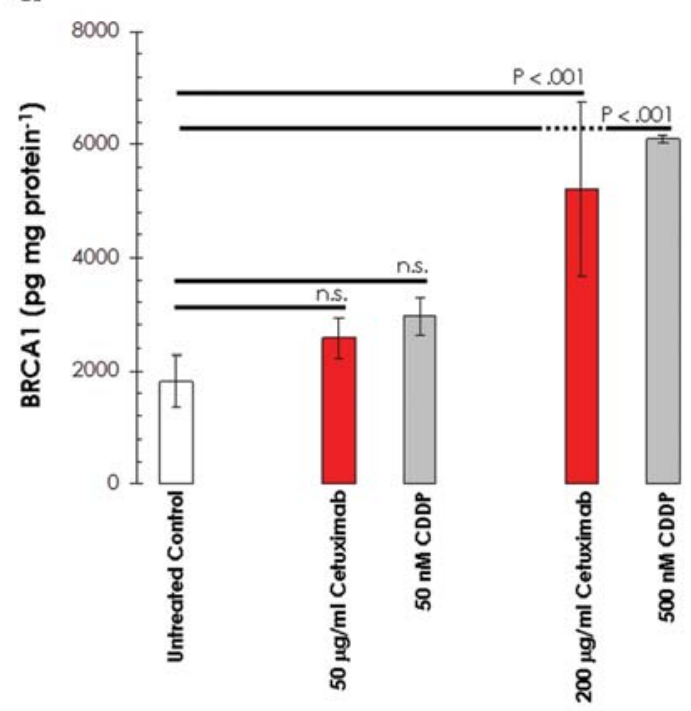

b

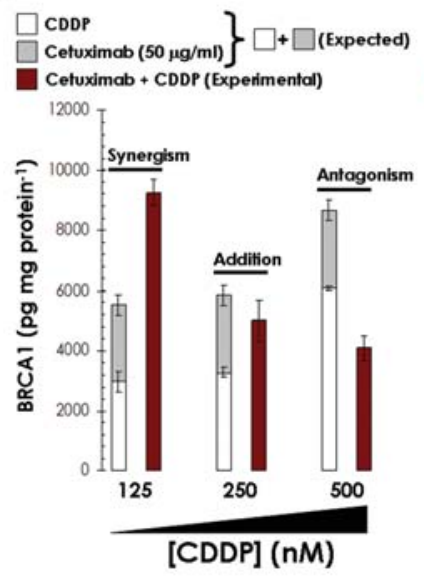

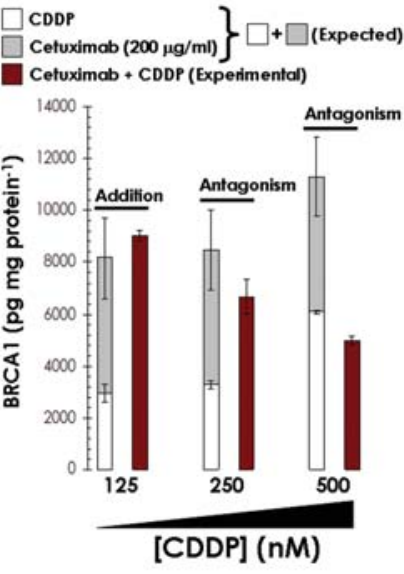

Figure 4. Effects of CDDP and Cetuximab in BRCA1 protein expression. (a) Overnight serum-starved MDA-MB-468 cells were cultured in standard culture conditions (i.e. $10 \%$ FBS) in the absence or presence of Cetuximab or CDDP for $48 \mathrm{~h}$ as specified. A BRCA1-specific ELISA (Assay Designs) was used according to the manufacturer's instructions to quantitatively evaluate BRCA1 concentrations (pg of BRCA1 per mg of protein) in whole cell lysates. Results are means (columns) and 95\% confidence intervals (bars) of three independent experiments made in triplicate. One-factor ANOVA was used to analyze differences in the amounts of BRCA1 (one-factor analysis of variance). All statistical tests were two-sided. (b) Analyses of combined drug effect in BRCA1 protein levels were performed developing additive models of interaction using experimental data obtained as described above. For each pair of columns, the height of the columns of the left represents the sum of the effect of each agent and, therefore, the expected BRCA1 protein expression if their effect is additive when used in combination. The total height of the columns on the right indicates the observed BRCA1 protein expression when the agents are used in combination. The difference between the heights of the paired columns reflects the magnitude of antagonism/synergism at changing BRCA1 protein levels.

(21-23). Of note, unlike other basal-like breast cancer models MDA-MB-468 cells do not carry mutations of the key DNA repair gene BRCA1 (24). When we employed ELISA-based quantitative analyses to measure BRCA1 protein levels in $\mathrm{CDDP}^{+/-}$Cetuximab-treated cells, we first observed that Cetuximab as single agent was as efficient as CDDP at increasing BRCA1 protein expression in MDA-MB-468 cells (Fig. 4a). Interestingly, Cetuximab co-exposure significantly antagonized the ability of CDDP to up-regulate BRCA1 expression in a dose-dependent manner (Fig. 4b). This antagonism was more significant when combining Cetuximab with a high dose of CDDP.

Cetuximab treatment significantly alters the phospho-proteome of MDA-MB-468 basal-like breast cancer cells. Cetuximab's mechanism of action is thought to involve the binding of Cetuximab to the EGFR, preventing normal ligand binding and subsequent activation of the EGFR-associated tyrosine kinase activity. To simultaneously assess the activation status of multiple receptor tyrosine kinases (RTKs) in the absence or presence or Cetuximab, we took advantage of the recently developed Human Phospho-RTK and Human PhosphoMAPK arrays, two rapid, sensitive and semi-quantitative tools able to simultaneously identify the levels of phosphorylation of multiple RTKs and of intracellular kinases without performing numerous immunoprecipitation and/or immunoblotting analyses. Phosphor-RTK profiling of cell lysates from serum-starved MDA-MB-468 cells clearly revealed that this basal-like breast cancer model largely depends on EGFR activation to proliferate as EGFR was the sole receptor significantly phosphorylated among 42 different RTKs (Fig. 5). Surprisingly, long-term treatment
(48 h) with high-dose Cetuximab $(200 \mu \mathrm{g} / \mathrm{ml})$ noticeably increased the activation status of HER1. This induction of EGFR after treatment with Cetuximab likely was due to receptor homodimerization and autophosphorylation because no significant changes were observed in the phosphorylation status of other members of the EGFR/HER network (i.e., HER2, HER3, HER4; Fig. 5). Immunoblotting procedures confirmed that treatment with Cetuximab led to EGFR activation due to hyper-phosphorylation of the tyrosine 1045 residue (data not shown).

Since Cetuximab treatment did not show the expected reduction or even loss of EGFR-phosphorylation but rather induction of receptor phosphorylation, it was relevant to evaluate the phosphorylation status of downstream intracellular kinases in the absence or presence of Cetuximab. Downstream of HER1, MDA-MB-468 cells exhibited constitutive activation (i.e., phosphorylation) of ERK1/ERK2, p38 $\alpha$ MAPK and AKT (Fig. 5). Notably, Cetuximab treatment drastically reduced phosphor-ERK1/ERK2 whereas marginal inhibiting effects were observed in the activation status of p38 $\alpha$ MAPK and AKT. Therefore, the anti-proliferative Cetuximab's mechanism of action against MDA-MB-468 basal-like breast cancer cells paradoxically appears to (up-stream) involve HER1 hyperactivation driven by HER1 homodimerization concomitantly with specific inactivation of the (downstream) MEK/ERK transduction cascade.

CDDP interacts with Cetuximab at decreasing EGFR protein expression in MDA-MB-468 basal-like breast cancer cells. Ligand-binding results in EGFR dimerization and autophosphorylation of its cytoplasmic $\mathrm{COOH}$-terminal domain (25-28). Once activated (i.e. phosphorylated) EGFR can further activate 


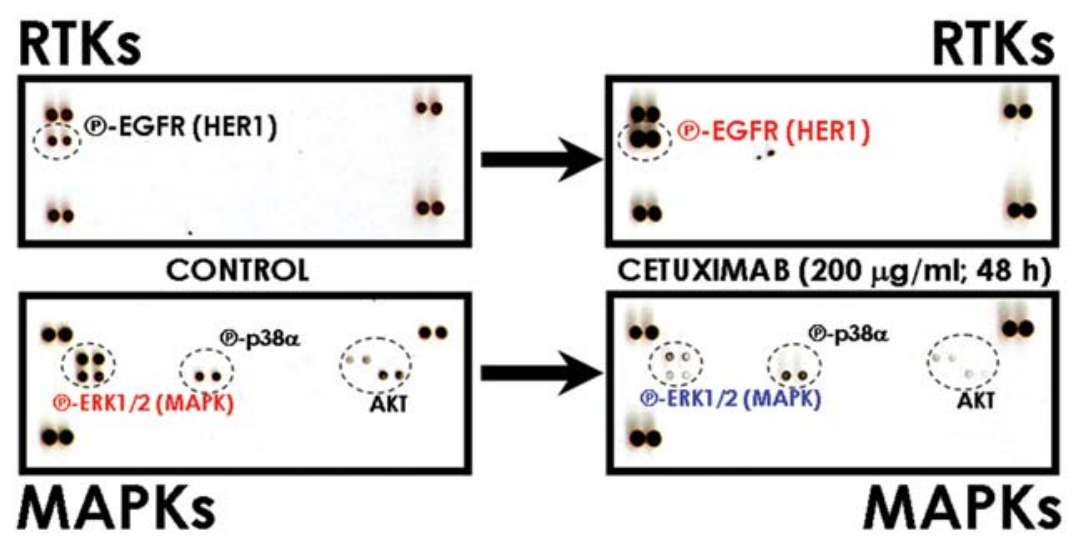

Figure 5. Phosphor-proteome profiling of MDA-MB-468 cells prior and after treatment with Cetuximab. Total cell lysates (750 $\mu \mathrm{g}$ ) from MDA-MB-468 prior and after treatment with $200 \mu \mathrm{g} / \mathrm{ml}$ Cetuximab (48 h) were incubated with membranes of the Human Phospho-RTK (top panels; 42 different RTKs) and Human Phospho-MAPK (bottom panels; 23 different MAPKs and other serine/threonine kinases) Array Kits (Proteome Profiler ${ }^{\mathrm{TM}}$; R\&D Systems) as per manufacturer's instructions. Phospho-RTK Array data were developed on X-ray film following exposure to chemiluminescent reagents. Figure shows representative phosphor-proteome analyses. Equivalent results were obtained in three independent experiments.

a

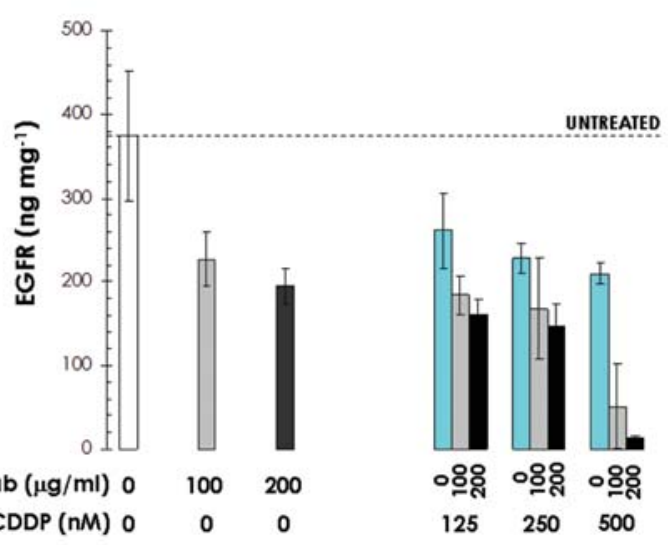

b

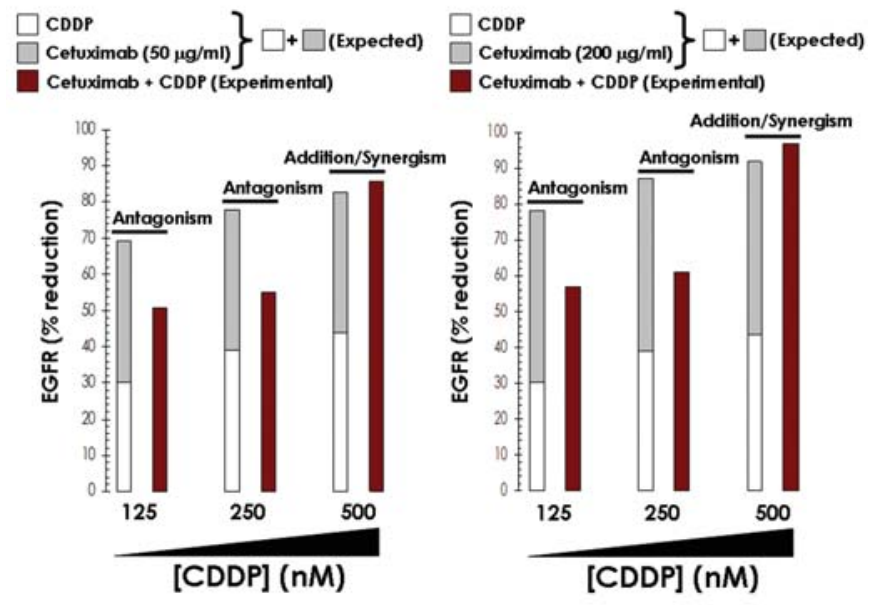

Figure 6. Effects of Cetuximab and/or CDDP in EGFR protein expression. (a) Overnight serum-starved MDA-MB-468 cells were cultured in low-serum conditions (i.e. 0.1\% FBS) in the absence or presence of Cetuximab and/or CDDP for $48 \mathrm{~h}$ as specified. The Oncogene Science HER1 (EGFR) microtiter ELISA was used according to the manufacturer's instructions to quantitatively evaluate HER1 concentrations (ng of EGFR per mg of protein) in whole cell lysates. Results are means (columns) and 95\% confidence intervals (bars) of three independent experiments made in triplicate. One-factor ANOVA was used to analyze differences in the amounts of HER1 (one-factor analysis of variance). All statistical tests were two-sided. (b) Analyses of combined drug effect in EGFR protein levels were performed developing additive models of interaction using experimental data obtained as described above. For each pair of columns, the height of the columns of the left represents the sum of the effect of each agent and, therefore, the expected EGFR protein expression if their effect is additive when used in combination. The total height of the columns on the right indicates the observed EGFR protein expression when the agents are used in combination. The difference between the heights of the paired columns reflects the magnitude of antagonism/synergism at changing EGFR protein levels.

different transduction cascades such as the ERK/MEK leading to transcription of EGFR-dependent genes. After ligandstimulation and internalization of EGFR, the receptor either recycles back to plasma membrane or is directed to the lysosomal compartment for degradation (25-28). In this regard, it is widely accepted that downregulation of EGFR due to internalization and subsequent lysosomal degradation is one mechanism that is targeted by diverse anti-EGFR therapies including Cetuximab $(29,30)$. Given that treatment of MDAMB-468 basal-like breast cancer cells with the EGFR-specific inhibitor Cetuximab paradoxically resulted in EGFR activation due to hyperphosphorylation with a concomitant reduction in ERK1/ERK2 phosphorylation levels, we finally sought to evaluate the influence that Cetuximab and/or CDDP have on EGFR protein expression in MDA-MB-468 cells. We assessed the expression levels of EGFR in whole cell lysates from MDA-MB-468 cells following treatment with Cetuximab in the absence or presence or increasing concentrations of CDDP (Fig. 6a). ELISA-based quantitative analyses showed that Cetuximab, as single agent, likewise reduced EGFR protein levels by $48 \%$ when compared to untreated control cells. Surprisingly, a high dose of CDDP (i.e. 500 nM CDDP) was as efficient as Cetuximab at decreasing EGFR protein expression (44\% reduction). Moreover, simultaneous exposure to optimal doses of Cetuximab and CDDP completed depleted EGFR protein (97\% reduction) in MDA-MB-468 cells 

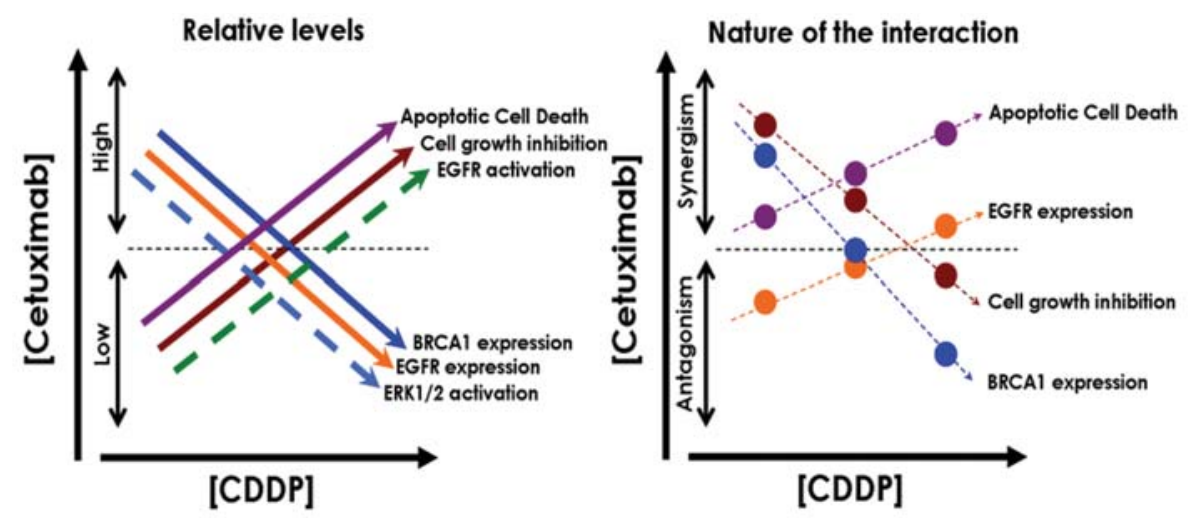

Figure 7. Summary of the relative levels (low/high) and the nature of the interactions (antagonism/synergism) occurring when analyzing cell growth inhibition, apoptotic cell death, EGFR expression/activation, BRCA1 expression and ERK1/2 activation in MDA-MB-468 cells as a function of Cetuximab and CDDP concentrations.

(Fig. 6a). Additive models of interactions revealed that antagonistic interactions occurred when Cetuximab was concurrently combined with low doses of CDDP, whereas additive to synergistic effects took place in the presence of an optimal concentration of CDDP (Fig. 6b).

\section{Discussion}

There is an urgent need for new therapies capable of managing basal-like breast carcinomas, a subtype of breast cancer-gene expression signature associated with poor relapse-free and overall survival that accounts for $15-25 \%$ of all breast-cancer cases (6-13). In this regard, the interaction between EGFR inhibitors (i.e. monoclonal antibodies such as Cetuximab and small molecule TKIs such as gefitinib) and DNA cross-linking agents (e.g. platinum derivatives) has been suggested to represent a promising combination for the treatment of triple-negative/basal-like breast tumors. On the one hand, the EGFR-pathway has become a potential target in the basal-like breast cancer subtype because at least $50 \%$ of basal-like tumors overexpress EGFR as assessed by immunohistochemistry (IHC). On the other hand, the implicated function of the BRCA1-dependent DNA repair pathway in the basal-like subtype is such that BRCA1 mutation carriers are likely to develop tumors of the basallike phenotype while diminished or absent expression occurs in subgroups of sporadic basal-like breast tumors. Moreover, given that BRCA1-deficient cells exhibit an exacerbated sensitivity to CDDP when compared to BRCA1 wild-type cells, the combination of an EGFR inhibitor and a platinum drug is expected to promote strong anti-proliferative effects against basal-like breast cancer cells $(16,17)$.

Although the above findings provide a compelling rationale for testing combinations of CDDP with agents (e.g. Cetuximab) that target specifically pathways that are essential for basal-like breast cancer cell maintenance (e.g. EGFR), it has been recently revealed that whereas functional loss of BRCA1 can lead to an accumulation of genetic events that result in cancer (e.g. basal-like breast carcinomas), once the disease is established, BRCA1 deficiency is no longer required or advantageous. Indeed, several recent studies examining how resistance to CDDP or inhibitors of the poly(ADP-ribose) polymerase (PARP), which selectively kill BRCA-deficient cells develops in primary cancers associated with dysfunctional BRCA 1 have established that resistance correlates with restoration of detectable levels of BRCA1 protein as results of either secondary mutations that restore the reading frame of the proteins or restoration of this pathway through demethylation of one of the Fanconi Anemia genes (FANCF) (31-35). We tested the nature of the interaction (i.e. antagonism, addition and synergism) of Cetuximab combined with CDDP using MDA-MB-468 cells, the main 'EGFRpositive' breast cancer model of resistance to EGFR TKIs $(14,15)$. Besides EGFR overexpression, the MDA-MB-468 breast cancer cell line shows many of the recurrent basal-like molecular abnormalities including ER-PR-HER2-(triple) negative status, TP53 deficiency, PTEN loss and constitutive activation of the intracellular signaling downstream of the EGFR (i.e. PI-3'K/AKT and MEK/ERK pathways). Unlike other basal-like breast cancer models, MDA-MB-468 cells do not carry mutations of the key DNA repair gene BRCA1 and they express relatively high levels of BRCA1 protein. Moreover, BRCA1 depletion has been found to decrease DNA damage repair and cell survival in MDA-MB-468 cells when treated with DNA-damaging drugs (24). Therefore, gefitinibresistant MDA-MB-468 basal-like breast cancer cells offer a unique molecular scenario including all the triple-negative/ basal-like molecular features in the presence of a functional BRCA1 pathway.

Our findings not only agree with the observation that most antibody-based biologically targeted agents (e.g. trastuzumab, pertuzumab, etc.) typically show low anti-proliferative rates when tested alone (a modest $57 \%$ reduction in cell viability occurred in EGFR-overexpressing MDA-MB-468 cells upon exposure to doses of Cetuximab as high as $200 \mu \mathrm{g} / \mathrm{ml}$ ) but further reveal that relative breast cancer cell sensitivity to the anti-EGFR antibody Cetuximab closely correlates with breast cancer cell type [i.e. triple-negative/basal-like (responsive) vs. luminal and HER2+ (non-responsive)]. In our hands, concurrent treatment with low doses of Cetuximab synergistically enhanced CDDP-induced apoptotic cell death. However, an isobologram-based mathematical assessment of the true nature of the interaction revealed a loss of synergism when employing a high-dose of Cetuximab. Using two ERnegative and HER2 non-amplified tumor derived cell lines, SUM149 and SUM102, which have been previously shown 
to express EGFR and show basal-like expression profilesHoadley et al recently reported that the combination of Cetuximab and carboplatin was highly synergistic at low doses of each drug (13). Moreover, they found that shortterm co-treatment of Cetuximab with carboplatin was antagonistic. Since the carboxyl-terminal domain of BRCA1 is required for the CDDP-induced recruitment of RAD51 to the DNA-damage site, a major contributing factor to breast cancer cell response to CDDP is decreased functional expression of BRCA1 (21-24). In the Hoadley basal-like tumor-derived cell lines, it has been reported that the SUM149 cell line has a BRCA1 mutation while the SUM102 cell line has barely detectable transcript levels of BRCA1. Accordingly, these BRCA1-deficient cells exhibited increased sensitivity to carboplatin compared to BRCA1wild-type cells. Using an ELISA-based quantitative approach, we found that CDDP-hypersensitive MDA-MB468 basal-like breast cancer cells express BRCA1 protein levels as high as those found in CDDP-resistant MCF-7 cells. Therefore, the functional status of BRCA1 does not appear to be the sole molecular determinant for CDDP sensitivity in EGFR-overexpressing basal-like breast carcinoma cells. Although we acknowledge that measurements of DNA adducts for the assessment of DNA damage repair were not performed in our study, BRCA1 up-regulation is associated with repair-mediated resistance to CDDP and ELISA-based quantitative analyses of BRCA1 protein levels might be viewed as an indirect measurement of DNA damage. Cetuximab as single agent was as efficient as CDDP at upregulating BRCA1 protein expression. Interestingly, Cetuximab co-exposure significantly antagonized the ability of CDDP to up-regulate BRCA1 expression. These findings strongly suggest that Cetuximab might potentiate the CDDPmediate cytotoxic effect as the result of inhibition of BRCA1-regulated nucleotide excision repair (NER) process triggered by CDDP-induced DNA lesions. In this regard, Balin-Gauthier et al recently reported that Cetuximab stimulates oxaliplatin-DNA adduct formation associated with reduced expression of the key enzyme (excision repair cross complementation group1: ERCC1) in the key repair process of oxaliplatin-DNA platinum adduct, the NER, both at the mRNA and protein levels $(36,37)$. Nevertheless, BRCA1 participates in both checkpoint and repair pathways in DNAdamaged cells and Cetuximab-induced changes in BRCA1 expression may profoundly alter cell cycle distribution in $\mathrm{G}_{1}$ checkpoint-compromised MDA-MB-468 (p53\% and pRb\%). Besides, there may be a regulation of BRCA1 mRNA by CDDP and/or Cetuximab that merits to be evaluated in forthcoming studies (38-40).

High expression of the genes in the EGFR-RAS-MEK pathway significantly correlates with the basal-like breast cancer subtype (11-13). Here, low-scale phosphoproteome analyses clearly revealed that cell proliferation in MDA-MB468 basal-like breast cancer cells largely depends on the hyperactivation of EGFR. Our findings further showed that interrupting EGFR signaling using Cetuximab mainly affects the down-stream activity of the MEK/ERK signaling cascade. Thus, when we analyzed the activation status of all three major MAPKs, ERK1/ERK2, JNK1-3, and p38 MAPKs, and other intracellular kinases, such as AKT, GSK-3, RSK1/RSK2,
MSK1/MSK2 and p70S6K1, the MEK target ERK was the sole kinase activity entirely inhibited by the EGFR inhibitor Cetuximab. Similar to EGF, Cetuximab induced hyperphosphorylation of EGFR accompanied by a sustained downregulation of EGFR protein expression. In contrast to the effects of EGF, however, Cetuximab treatment fully deactivated ERK activity. These findings further support pioneering findings by Mandic et al who reported that treatment of head and neck squamous cell carcinomas with Cetuximab did not show reduction but rather induction of receptor phosphorylation that was accompanied by EGFRinternalization and degradation as observed after treatment with the EGFR ligand EGF (41). It is reasonable to suggest that Cetuximab, which was originally designed to block the extracellular ligand binding site of EGFR, appears to function as a pure EGFR agonist mimicking EGFR ligands. Importantly, EGFR hyperactivation induced by Cetuximab was not accompanied by receptor turnover or by activation of the ERK and AKT downstream signaling pathways that control cell proliferation and survival. Therefore, Cetuximabtargeted (hyperphosphorylated) EGFR population in basal-like breast cancer cells should be separated to a subcellular compartment and/or is blocked by other molecules and thereby cannot exert downstream signaling events. Preliminary experiments in our laboratory suggest that subcellular compartmentalization of phosphor-EGFR in EGFR-dependent cancer cells strongly diverges in the absence or presence of Cetuximab (unpublished observations).

Our current evaluation of the growth and molecular interactions of Cetuximab and CDDP in the gefitinib-resistant MDA-MB-468 basal-like breast cancer cell line preclinically supports, at least in part, ongoing clinical trials of 'triplenegative/basal-like' metastatic breast cancer patients who are receiving either Cetuximab alone versus Cetuximab plus carboplatin (http://www.clinicaltrials.gov/ct/show/NCT0023 2505). However, our current findings further suggest that treatment schedule, Cetuximab and/or CDDP doses and EGFR/BRCA1 status should be carefully considered when combining Cetuximab and platinum derivatives in sporadic basal-like breast carcinomas (Fig. 7). Specifically, if Cetuximab enhances the chemoresponse of triple-negative/ basal-like breast cancer cells by suppressing cellular DNA repair capacity, thereby prolonging the presence of CDDPinduced DNA adducts, it is reasonable to suggest that CDDP followed by an equiactive relative dose of Cetuximab is an appropriate combination of evaluation in triple-negative/ basal-like breast carcinomas. Using human KYSE30 esophageal squamous epithelial cancer cells, an in vitro model of an EGFR-positive human epithelial cell line with a functional EGFR-dependent autocrine growth pathway, early studies by Morelli et al clearly demonstrated that only when KYSE30 cancer cells were first exposed to a cytotoxic drug (e.g., oxaliplatin) and then treated with Cetuximab a frankly synergistic growth inhibitory effect was observed (42). Pre-clinical and clinical studies are warranted to definitely evaluate whether the best treatment schedule when using EGFR targeted agents such as Cetuximab in a clinical setting would be a sequence in which cytotoxic drug treatment is followed by EGFR inhibitor administration. 
Studies by Pietras et al firstly showed that the use of the anti-HER2 monoclonal antibody trastuzumab (Herceptin $\left.{ }^{\circledR}\right)$ in combination with CDDP in breast carcinomas cells in culture, human breast cancer xenografts and in patients with HER2overexpressing metastatic breast cancer, results in tumoricidal effects higher than those reported for trastuzumab or CDDP alone. This synergistic therapeutic interaction, which is largely due to anti-HER2 receptor antibody-induced blockade of CDDP-DNA adduct repair, termed receptor enhanced chemosensitivity (REC) was suggested to specifically target HER2-overexpressing cancer cells (43-47). We previously demonstrated that this REC mechanism is similarly pronounced in breast cancer cells overexpressing the combinatorial HER3 ligand Heregulin (HRG), a trastuzumabsensitive breast cancer subtype of EGFR-positive cells that do not overexpress HER2 (48). We now report that a clinically valuable Cetuximab-induced REC effect further occurs in EGFR-overexpressing triple-negative/basal-like breast carcinoma cells.

\section{Acknowledgements}

Cristina Oliveras-Ferraros participated in this study supported by Merck Serono España (Madrid, Spain). Javier A. Menendez is the recipient of a Basic, Clinical and Translational Research Award (BCTR0600894) from the Susan G. Komen Breast Cancer Foundation (TX, USA). This study was supported in part by Instituto de Salud Carlos III (Ministerio de Sanidad y Consumo, Fondo de Investigación Sanitaria -FIS-, Spain, Grants CP05-00090 and PI06-0778 to Javier A. Menendez, and Grant RD06-0020-0028 to Javier A. Menendez, Joan Brunet and Begoña Martin-Castillo). Javier A. Menendez was also supported by a Grant from the Fundación Científica de la Asociación Española Contra el Cáncer (AECC, Spain).

\section{References}

1. Perou CM, Sørlie T, Eisen MB, van de Rijn M, Jeffrey SS, Rees CA, Pollack JR, Ross DT, Johnsen H, Akslen LA, Fluge O, Pergamenschikov A, Williams C, Zhu SX, Lønning PE, Børresen-Dale AL, Brown PO and Botstein D: Molecular portraits of human breast tumours. Nature 406: 747-752, 2000.

2. Sørlie T, Perou CM, Tibshirani R, Aas T, Geisler S, Johnsen H, Hastie T, Eisen MB, van de Rijn M, Jeffrey SS, Thorsen T, Quist H, Matese JC, Brown PO, Botstein D, Eystein Lønning P and Børresen-Dale AL: Gene expression patterns of breast carcinomas distinguish tumor subclasses with clinical implications. Proc Natl Acad Sci USA 98: 10869-10874, 2001.

3. Sorlie T, Tibshirani R, Parker J, Hastie T, Marron JS, Nobel A, Deng S, Johnsen H, Pesich R, Geisler S, Demeter J, Perou CM, Lønning PE, Brown PO, Børresen-Dale AL and Botstein D: Repeated observation of breast tumor subtypes in independent gene expression data sets. Proc Natl Acad Sci USA 100: 8418-8423, 2003.

4. Sotiriou C, Neo SY, McShane LM, Korn EL, Long PM, Jazaeri A, Martiat P, Fox SB, Harris AL and Liu ET: Breast cancer classification and prognosis based on gene expression profiles from a population-based study. Proc Natl Acad Sci USA 100: 10393-10398, 2003.

5. Hu Z, Fan C, Oh DS, Marron JS, He X, Qaqish BF, Livasy C, Carey LA, Reynolds E, Dressler L, Nobel A, Parker J, Ewend MG, Sawyer LR, Wu J, Liu Y, Nanda R, Tretiakova M, Ruiz Orrico A, Dreher D, Palazzo JP, Perreard L, Nelson E, Mone M, Hansen H, Mullins M, Quackenbush JF, Ellis MJ, Olopade OI, Bernard PS and Perou CM: The molecular portraits of breast tumors are conserved across microarray platforms. BMC Genomics 7: 96, 2006.
6. Nielsen TO, Hsu FD, Jensen K, Cheang M, Karaca G, Hu Z, Hernandez-Boussard T, Livasy C, Cowan D, Dressler L, Akslen LA, Ragaz J, Gown AM, Gilks CB, van de Rijn M and Perou CM: Immunohistochemical and clinical characterization of the basal-like subtype of invasive breast carcinoma. Clin Cancer Res 10: 5367-5374, 2004.

7. Rakha EA, Tan DS, Foulkes WD, Ellis IO, Tutt A, Nielsen TO and Reis-Filho JS: Are triple-negative tumours and basal-like breast cancer synonymous? Breast Cancer Res 9: 404; author reply $405,2007$.

8. Cheang MC, Voduc D, Bajdik C, Leung S, McKinney S, Chia SK, Perou CM and Nielsen TO: Basal-like breast cancer defined by five biomarkers has superior prognostic value than triple-negative phenotype. Clin Cancer Res 14: 1368-1376, 2008.

9. Diaz LK, Cryns VL, Symmans WF and Sneige N: Triple negative breast carcinoma and the basal phenotype: from expression profiling to clinical practice. Adv Anat Pathol 14: 419-430, 2007.

10. Reis-Filho JS and Tutt AN: Triple negative tumours: a critical review. Histopathology 52: 108-118, 2008.

11. Yehiely F, Moyano JV, Evans JR, Nielsen TO and Cryns VL: Deconstructing the molecular portrait of basal-like breast cancer. Trends Mol Med 12: 537-544, 2006.

12. Moyano JV, Evans JR, Chen F, Lu M, Werner ME, Yehiely F, Diaz LK, Turbin D, Karaca G, Wiley E, Nielsen TO, Perou CM and Cryns VL: AlphaB-crystallin is a novel oncoprotein that predicts poor clinical outcome in breast cancer. J Clin Invest 116: 261-270, 2006.

13. Hoadley KA, Weigman VJ, Fan C, Sawyer LR, He X, Troester MA, Sartor CI, Rieger-House T, Bernard PS, Carey LA and Perou CM: EGFR associated expression profiles vary with breast tumor subtype. BMC Genomics 8: 258, 2007.

14. Normanno N, De Luca A, Maiello MR, Campiglio M, Napolitano M, Mancino M, Carotenuto A, Viglietto G and Menard S: The MEK/MAPK pathway is involved in the resistance of breast cancer cells o the EGFR tyrosine kinase inhibitor gefitinib. J Cell Physiol 207: 420-427, 2006.

15. Ferrer-Soler L, Vazquez-Martin A, Brunet J, Menendez JA, De Llorens R and Colomer R: An update of the mechanisms of resistance to EGFR-tyrosine kinase inhibitors in breast cancer: Gefitinib (Iressa) -induced changes in the expression and nucleo-cytoplasmic trafficking of HER-ligands (Review). Int J Mol Med 20: 3-10, 2007.

16. Tischkowitz MD and Foulkes WD: The basal phenotype of BRCA1-related breast cancer: past, present and future. Cell Cycle 5: 963-967, 2006.

17. Turner NC and Reis-Filho JS: Basal-like breast cancer and the BRCA1 phenotype. Oncogene 25: 5846-5853, 2006.

18. Fadare $\mathrm{O}$ and Tavassoli FA: Clinical and pathologic aspects of basal-like breast cancers. Nat Clin Pract Oncol 5: 149-159, 2008.

19. Berenbaum MC: What is synergy? Pharmacol Rev 41: 93-193, 1989.

20. Sarrió D, Rodriguez-Pinilla SM, Hardisson D, Cano A, Moreno-Bueno G and Palacios J: Epithelial-mesenchymal transition in breast cancer relates to the basal-like phenotype. Cancer Res 68: 989-997, 2008.

21. Zhou C, Huang P and Liu J: The carboxyl-terminal of BRCA1 is required for subnuclear assembly of RAD51 after treatment with cisplatin but not ionizing radiation in human breast and ovarian cancer cells. Biochem Biophys Res Commun 336: 952-960, 2005.

22. Bhattacharyya A, Ear US, Koller BH, Weichselbaum RR and Bishop DK: The breast cancer susceptibility gene BRCA1 is required for subnuclear assembly of Rad5 1 and survival following treatment with the DNA cross-linking agent cisplatin. J Biol Chem 275: 23899-23903, 2000.

23. Husain A, He G, Venkatraman ES and Spriggs DR: BRCA1 up-regulation is associated with repair-mediated resistance to cis-diamminedichloroplatinum(II). Cancer Res 58: 1120-1123, 1998.

24. Crowe DL and Lee MK: New role for nuclear hormone receptors and coactivators in regulation of BRCA1-mediated DNA repair in breast cancer cell lines. Breast Cancer Res 8: R1, 2006.

25. Dikic I: Mechanisms controlling EGF receptor endocytosis and degradation. Biochem Soc Trans 31: 1178-1181, 2003.

26. Wiley HS: Trafficking of the ErbB receptors and its influence on signaling. Exp Cell Res 284: 78-88, 2003.

27. Yarden Y and Sliwkowski MX: Untangling the ErbB signalling network. Nat Rev Mol Cell Biol 2: 127-137, 2001. 
28. Waterman $\mathrm{H}$ and Yarden Y: Molecular mechanisms underlying endocytosis and sorting of ErbB receptor tyrosine kinases. FEBS Lett 490: 142-152, 2001

29. Sunada H, Magun BE, Mendelsohn J and MacLeod CL: Monoclonal antibody against epidermal growth factor receptor is internalized without stimulating receptor phosphorylation. Proc Natl Acad Sci USA 83: 3825-3829, 1986.

30. Hynes NE and Lane HA: ERBB receptors and cancer: the complexity of targeted inhibitors. Nat Rev Cancer 5: 341-354, 2005. Erratum in: Nat Rev Cancer 5: 580, 2005.

31. Sakai W, Swisher EM, Karlan BY, Agarwal MK, Higgins J, Friedman C, Villegas E, Jacquemont C, Farrugia DJ, Couch FJ, Urban $\mathrm{N}$ and Taniguchi T: Secondary mutations as a mechanism of cisplatin resistance in BRCA2-mutated cancers. Nature 451: 1116-1120, 2008.

32. Edwards SL, Brough R, Lord CJ, Natrajan R, Vatcheva R, Levine DA, Boyd J, Reis-Filho JS and Ashworth A: Resistance to therapy caused by intragenic deletion in BRCA2. Nature 451: 1111-1115, 2008

33. Swisher EM, Sakai W, Karlan BY, Wurz K, Urban N and Taniguchi T: Secondary BRCA1 mutations in BRCA1-mutated ovarian carcinomas with platinum resistance. Cancer Res 68: 2581-2586, 2008.

34. Shah NP: Bench to bedside: BRCA: from therapeutic target to therapeutic shield. Nat Med 14: 495-496, 2008.

35. Taniguchi T, Tischkowitz M, Ameziane N, Hodgson SV, Mathew CG, Joenje H, Mok SC and D'Andrea AD: Disruption of the Fanconi anemia-BRCA pathway in cisplatin-sensitive ovarian tumors. Nat Med 9: 568-574, 2003.

36. Balin-Gauthier D, Delord JP, Rochaix P, Mallard V, Thomas F, Hennebelle I, Bugat R, Canal P and Allal C: In vivo and in vitro antitumor activity of oxaliplatin in combination with cetuximab in human colorectal tumor cell lines expressing different level of EGFR. Cancer Chemother Pharmacol 57: 709-718, 2006.

37. Balin-Gauthier D, Delord JP, Pillaire MJ, Rochaix P, Hoffman JS, Bugat R, Cazaux C, Canal P and Allal BC: Cetuximab potentiates oxaliplatin cytotoxic effect through a defect in NER and DNA replication initiation. Br J Cancer 98: 120-128, 2008.

38. Yarden RI and Papa MZ: BRCA1 at the crossroad of multiple cellular pathways: approaches for therapeutic interventions. Mol Cancer Ther 5: 1396-1404, 2006.

39. Mullan PB, Quinn JE and Harkin DP: The role of BRCA1 in transcriptional regulation and cell cycle control. Oncogene 25: $5854-5863,2006$
40. Deng CX: BRCA1: cell cycle checkpoint, genetic instability, DNA damage response and cancer evolution. Nucleic Acids Res 34: 1416-1426, 2006

41. Mandic R, Rodgarkia-Dara CJ, Zhu L, Folz BJ, Bette M, Weihe E, Neubauer A and Werner JA: Treatment of HNSCC cell lines with the EGFR-specific inhibitor cetuximab (Erbitux) results in paradox phosphorylation of tyrosine 1173 in the receptor. FEBS Lett 580: 4793-4800, 2006.

42. Morelli MP, Cascone T, Troiani T, De Vita F, Orditura M, Laus G, Eckhardt SG, Pepe S, Tortora G and Ciardiello F: Sequence-dependent antiproliferative effects of cytotoxic drugs and epidermal growth factor receptor inhibitors. Ann Oncol 16 (Suppl 4): 61-68, 2005.

43. Pietras RJ, Fendly BM, Chazin VR, Pegram MD, Howell SB and Slamon DJ: Antibody to HER-2/neu receptor blocks DNA repair after cisplatin in human breast and ovarian cancer cells. Oncogene 9: 1829-1838, 1994.

44. Arteaga CL, Winnier AR, Poirier MC, Lopez-Larraza DM, Shawver LK, Hurd SD and Stewart SJ: p185c-erbB-2 signal enhances cisplatin-induced cytotoxicity in human breast carcinoma cells: association between an oncogenic receptor tyrosine kinase and drug-induced DNA repair. Cancer Res 54: 3758-3765, 1994

45. Pietras RJ, Pegram MD, Finn RS, Maneval DA and Slamon DJ: Remission of human breast cancer xenografts on therapy with humanized monoclonal antibody to HER-2 receptor and DNAreactive drugs. Oncogene 17: 2235-2249, 1998

46. Pegram MD, Lipton A, Hayes DF, Weber BL, Baselga JM, Tripathy D, Baly D, Baughman SA, Twaddell T, Glaspy JA and Slamon DJ: Phase II study of receptor-enhanced chemosensitivity using recombinant humanized anti-p185HER2/neu monoclonal antibody plus cisplatin in patients with HER2/neu-overexpressing metastatic breast cancer refractory to chemotherapy treatment. J Clin Oncol 16: 2659-2671, 1998.

47. Pegram MD and Slamon DJ: Combination therapy with trastuzumab (Herceptin) and cisplatin for chemoresistant metastatic breast cancer: evidence for receptor-enhanced chemosensitivity. Semin Oncol 26 (Suppl 12): 89-95, 1999.

48. Menendez JA, Mehmi I and Lupu R: Trastuzumab in combination with heregulin-activated Her-2 (erbB-2) triggers a receptorenhanced chemosensitivity effect in the absence of Her-2 overexpression. J Clin Oncol 24: 3735-3746, 2006. 